\title{
Fuzzy Analysis Of Social, Emotional Maturity Of Post Graduate Social Work Students In Trichy, Tamilnadu
}

\author{
K.Maheswari ${ }^{1}$, S.Kalaiselvan ${ }^{2} \&$ S.Narayanamoorthy ${ }^{3}$ \\ ${ }^{1,2}$ Department of Social Work, Bharathidasan University Constituent College, Perambalur, \\ Tamilnadu, India. \\ ${ }^{3}$ Department of Mathematics, Bharathiar University, Coimbatore-641 046, India.
}

\begin{abstract}
The main of this research paper is to study the social and emotional maturities of the postgraduate students in Tamilnadu, Trichy district in particular. For this we have interviewed 160 students in the study area using a linguistic questionnaire. As the problems faced by them at large, involved so much of feelings and uncertainties. We felt it to fit to use fuzzy theory in general and fuzzy relational maps in particular(FRMs).
\end{abstract}

Key Words: FRM, Fuzzy, Emotional Maturity, Social Maturity.

\section{INTRODUCTION}

Maturity is the ability to respond to the environment in an appropriate manner. This response is generally learned rather than instinctive, and is not determined by one's age. Emotional maturity is characterized by ability to become interested in things and persons; to do things for their own sake, to give love to other persons. By keeping these things in mind the researcher has planned to study the social,emotional maturities of the postgraduate students studying at Trichirappalli, Tamilnadu. Cole (1954) says, 'The chief index of emotional maturity is the ability to bear tension'. This view lays stress upon 'self-control' and not on 'self-fulfilment'. Dosanjh (1956) says, 'Emotional maturity means a balanced personality. It means ability to govern disturbing emotions, show steadiness and endurance under pressure and to be tolerant and free from neurotic tendencies'. Good (1981) has stated that emotional maturity refers to emotional patterns of an adult who has progressed through the inferior emotional stages characteristic of infancy, childhood and adolescence and is not fit to deal successfully with reality and in adult love relationship without under emotional strain. Jersild (1963) says, 'Emotional maturity means the degree to which person has realized his potential for richness of living and has developed his capacity to enjoy things, to relate himself to others, to love and to laugh; his capacity for whole hearted sorrow, when an occasion arises and his capacity to show fear when there is occasion to be frightened, without feeling a need to use a false mask of courage, such as must be assumed by persons afraid to admit that they are afraid'. According to Walter D. Smitson (1974), Emotional maturity is a process in which the personality is continuously striving for greater sense of emotional health, both intrapsychically and intrapersonally. As scientific analysis is preferred for analysing social problems, in this research paper, we analyse the social and emotional maturities of Postgraduate College Students using mathematical analysis in general and fuzzy mathematics in particular.

\section{FUZZY RELATIONAL MAPS (FRMS)}

In this section, we present the concepts of Fuzzy relational maps (FRMs), Thus for us to define a FRM we need a domain space and a range space which are disjoint in the sense of concepts. We further assume no intermediate relation exists within the domain elements or node and the range spaces elements. The number of elements in the range space need not in general be equal to the number of elements in the domain space. Thus throughout this section we assume the elements of the domain space are taken from the real vector space of dimension $\mathrm{n}$ and that of the range space are real vectors from the vector space of dimension $\mathrm{m}$ ( $\mathrm{m}$ in general need not be equal to $\mathrm{n}$ ).

Definition 2.1 : A FRM is a directed graph or a map from D to R with concepts like policies or events etc, as nodes and causalities as edges. It represents causal relations between spaces $\mathrm{D}$ and $\mathrm{R}$.

Definition 2.2: When the nodes of the FRM are fuzzy sets then they are called fuzzy nodes. FRMs with edge weights are called simple FRMs

Definition 2.3: Let $D_{1}, D_{2}, \ldots D_{n}$ be the nodes of the domain space $D$ of an FRM and $R_{1}, R_{2}, \ldots, R_{m}$ be the nodes of the range space $R$ of an FRM. Let the matrix $E$ be defined as $E=\left(e_{i j}\right)$ where $e_{i j}$ is the weight of the directed edge $D_{i} R_{j}\left(\right.$ or $\left.R_{j} D_{i}\right)$, E is called the relational matrix of the FRM. 
Definition 2.4: Let $D_{1}, D_{2}, \ldots D_{n}$ and $R_{1}, R_{2}, \ldots, R_{m}$ denote the nodes of the FRM. Let $A=\left(a_{1}, a_{2}, \ldots, a_{n}\right), a_{i} \in\{0$, $\pm 1\}$. A is called the instantaneous state vector of the domain space and it denotes the on-off position of the nodes at any instant. Similarly let $B=\left(b_{1}, b_{2}, \ldots, b_{m}\right) b_{i} \in\{0, \pm 1\}$. B is called instantaneous state vector of the range space and it denotes the on-off position of the nodes at any instant $a_{i}=0$ if $a_{i}$ is off and $a_{i}=1$ if $a_{i}$ is on for $i=1,2, \ldots, n$ Similarly, $b_{i}=0$ if $b_{i}$ is off and $b_{i}=1$ if $b_{i}$ is on, for $i=1,2, \ldots, m$.

Definition 2.5: Let $D_{1}, D_{2}, \ldots D_{n}$ and $R_{1}, R_{2}, \ldots, R_{m}$ be the nodes of an FRM. Let $D_{i} R_{j}\left(\right.$ or $\left.R_{j} D_{i}\right)$ be the edges of an FRM, $\mathrm{j}=1,2, \ldots, \mathrm{m}$ and $\mathrm{i}=1,2, \ldots, \mathrm{n}$. Let the edges form a directed cycle. An FRM is said to be a cycle if it posses a directed cycle. An FRM is said to be acyclic if it does not posses any directed cycle.

Definition 2.6: An FRM with cycles is said to be an FRM with feedback.

Definition 2.7: When there is a feedback in the FRM, i.e. when the causal relations flow through a cycle in a revolutionary manner, the FRM is called a dynamical system.

Definition 2.8: Let $D_{i} R_{j}\left(\right.$ or $\left.R_{j} D_{i}\right) 1 \leq j \leq m, 1 \leq i \leq n$. When $R_{i}\left(\right.$ or $\left.D_{j}\right)$ is switched on and if causality flows through edges of the cycle and if it again causes $R_{i}\left(\right.$ or $D_{j}$ ), we say that the dynamical system goes round and round. This is true for any node $R_{j}\left(\right.$ or $\left.D_{i}\right)$ for $1 \leq \mathrm{i} \leq \mathrm{n}$, $($ or $1 \leq \mathrm{j} \leq \mathrm{m})$. The equilibrium state of this dynamical system is called the hidden pattern.

Definition 2.9: If the equilibrium state of a dynamical system is a unique state vector, then it is called a fixed point. Consider an FRM with $R_{1}, R_{2}, \ldots, R_{m}$ and $D_{1}, D_{2}, \ldots D_{n}$ as nodes. For example, let us start the dynamical system by switching on $R_{1}$ (or $D_{1}$ ). Let us assume that the FRM settles down with $R_{1}$ and $R_{m}$ (or $D_{1}$ and $D_{n}$ ) on, i.e. the state vector remains as $(1,0, ., 0,1)$ in $\mathrm{R}$ (or $(1,0,0, ., 0,1)$ in $\mathrm{D})$, This state vector is called the fixed point.

Definition 2.10: If the FRM settles down with a state vector repeating in the form $A_{1} \rightarrow A_{2} \rightarrow A_{3} \rightarrow \ldots \rightarrow A_{i}$ $\rightarrow \mathrm{A}_{1}$ (or $\mathrm{B}_{1} \rightarrow \mathrm{B}_{2} \rightarrow \ldots \rightarrow \mathrm{B}_{\mathrm{i}} \rightarrow \mathrm{B}_{1}$ ) then this equilibrium is called a limit cycle.

\section{ADAPTATION OF FRM TO THE PROBLEM}

In this section, we illustrate the dynamical system by a very simple model. The following domain and range space are taken as the main node for study.

\section{Domain Space}

$\mathrm{D}_{1}$ - Social Maturity is High

$\mathrm{D}_{2}-$ Social Maturity is Low

$\mathrm{D}_{3}$ - Social and Emotional Maturity are Average

$\mathrm{D}_{4}$ - Emotional Maturity is High

$\mathrm{D}_{5}-$ Emotional Maturity is Low

\section{Range Space}

$\mathrm{R}_{1}$ - Fit to Social Work Profession

$\mathrm{R}_{2}$ - Not Fit to Social Work Profession

$\mathrm{R}_{3}-$ Average to Social Work Profession

We proceed on to give the opinion of the expert:

The relational directed graph of the social work student- profession model is given by the expert is as follows:

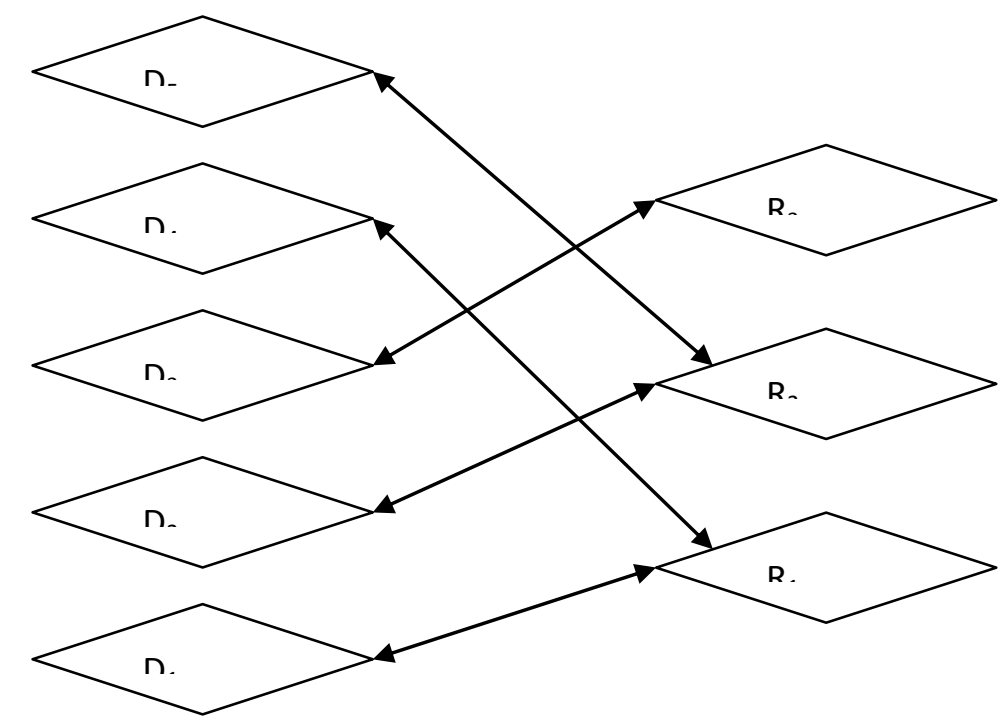


The relational matrix E got from the above relational map is

$$
E=\left[\begin{array}{lll}
1 & 0 & 0 \\
O & 1 & 0 \\
O & 0 & 1 \\
1 & 0 & 0 \\
0 & 1 & 0
\end{array}\right]
$$

Using the dynamical system given by the expert we determine the hidden pattern.

Let the initial input vector be $\mathrm{A}=\left(\begin{array}{lllll}1 & 0 & 0 & 0 & 0\end{array}\right)$, Where only the node "D1-Social Maturity is High" is in the ON State and all the nodes are in the OFF State.

$$
\text { Let } \begin{aligned}
\mathrm{A} & =\left(\begin{array}{lllll}
1 & 0 & 0 & 0 & 0
\end{array}\right) \\
\mathrm{AE} & =\left(\begin{array}{lllll}
1 & 0 & 0
\end{array}\right)=\mathrm{B} \\
\mathrm{BE}^{\mathrm{T}} & =\left(\begin{array}{lllll}
1 & 0 & 0 & 1 & 0
\end{array}\right)=\mathrm{A}_{1} \\
\mathrm{~A}_{1} \mathrm{E} & =\left(\begin{array}{lllll}
2 & 0 & 0
\end{array}\right) \mapsto\left(\begin{array}{lll}
1 & 0 & 0
\end{array}\right)=\mathrm{B}_{1} \\
\mathrm{~B}_{1} \mathrm{E}^{\mathrm{T}} & =\left(\begin{array}{lllll}
1 & 0 & 0 & 1 & 0
\end{array}\right)=\mathrm{A}_{1}
\end{aligned}
$$

After updating and thresholding the instantaneous vector at each stage we obtain the following chain:

$$
\mathrm{A}-\mathrm{B}-\mathrm{A}_{1}-\mathrm{B}_{1}-\mathrm{A}_{1}
$$

We see from the above the resultant is also a fixed point.

Now to anlyze the effect of $\mathrm{D}_{3}$ is ON State:

$$
\begin{aligned}
& \text { Let } \mathrm{M}=\left(\begin{array}{lllll}
0 & 0 & 1 & 0 & 0
\end{array}\right) \\
& \mathrm{ME}=\left(\begin{array}{llll}
0 & 0 & 1
\end{array}\right)=\mathrm{N} \\
& \mathrm{NE}^{\mathrm{T}}=\left(\begin{array}{lllll}
0 & 0 & 1 & 0 & 0
\end{array}\right)=\mathrm{M} \\
& \mathrm{M}-\mathrm{N}-\mathrm{M} \text { is a fixed point. }
\end{aligned}
$$

\section{CONCLUSION}

In this research paper, we analyzed the social and emotional maturities of the postgraduate students. When D1 is ON state which gives the $\mathrm{D}_{1}$ and $\mathrm{D}_{2} \mathrm{ON}$ and all other nodes comes to OFF state. From the expert opinion and resultant vector the awareness must be given on the need and importance of education and moral behaviour. Emotional Maturity is not only Emotional maturity at all levels will help a person to lead a healthy life. Skill development programmes and Vocational training programmes can be given to the students for their earned living.

\section{REFERENCES}

[1] Axelord, R., Structure of Decision: The Cognitive Maps of Political Elites, Princeton,NJ: Princeton iversity, Press, 1976.

[2] Bart Kosko. Fuzzy Cognitive Maps, International Journal of Man-machine Studies, v241986, pp. 65-75.

[3] Bart Kosko, Neural Networks and Fuzzy Systems, Prentice Hall of India Private Limited,

[4] 1997.

[5] Crow, L.D. and Crow, A. (1962). Child Development and Adjustment. New York: The McMillan company.

[6] Narayanamoorthy, S., A Fuzzy Analysis Of The Socio Economic Problems Faced By

[7] Bonded Labourers In Tamil Nadu, Unpublished Ph.D Thesis, University of Madras, (2007).

[8] Narayanamoorthy. S, Shanmugam. P. Application of Fuzzy Networks to Analyze the Socio- Economic Problems Faced by Cotton Mill Workers.International Journal of Mathematics and

[9] Computation, 2011, pp. 28-32.

[10] Punithavathi.S. Emotional Maturity and Decision Making Styles Among Arts and Scienceand Engineering College Women Students, Asia Pacific Journal of Marketing \& Management Review ISSN 2319-2836 Vol.2 (4), April (2013). 